\title{
Medical and Health Service Standardization of the International Organization for Standardization and Typical Countries in Asia-pacific Fei HOU ${ }^{1, a}$, Li-Li CAO ${ }^{1, b, *}$, Yi ZENG ${ }^{1, c, *}$, Yong-Hong CHENG ${ }^{1, d,{ }^{*}}$ \\ ${ }^{1}$ China National Institute of Standardization, Beijing, China \\ ahoufei@cnis.gov.cn, ${ }^{b} c a o l l @ c n i s . g o v . c n,{ }^{c} z e n g y i @ c n i s . g o v . c n,{ }^{d}$ chengyh@cnis.gov.cn \\ ${ }^{*}$ Corresponding author
}

Key Words: Medical and health service, Standardization, International Organization for Standardization, Asia-pacific.

\begin{abstract}
Medical and health service industry has been gradually becoming the new focus of international standardization in recent decades, by being viewed increasingly serious by many international organizations and some countries, who carrying out a series of fruitful work with lots of good effect. This paper analyzes the status of medical and health service standardization in the International Organization for Standardization, Japan and Australia, providing good experience and certain reference for China.
\end{abstract}

\section{Introduction}

With the improvement of living standards and the development of medical and healthcare technologies, life expectancy and life quality has been expected to be uplifted dramatically. Under such a background, medical and health service industry receives extensive attention and gains great significance worldwide; various countries share a common vision of helping people live a healthier, happier and more comfortable life.

In recent years, standardization, an important means to promote the development and management of service industry, has become increasingly popular among both international organizations, such as ISO, and many Asia-pacific countries, such as Japan and Australia. Actually, remarkable achievements have been made in exploring and implementing standardization of medical and health service industry around the world.

\section{International Organization for Standardization}

At the turn of the 21st century, International Organization for Standardization (hereinafter referred to as "ISO") began to shift its focus to service industries and put forwards the philosophy that standardization should better embody humanistic spirit, pay more attention to consumer rights protection, and achieve the goal of both improving life quality and promote interpersonal communication. Following this philosophy, ISO made great strides in the research and formulation of standards for the service industry, releasing lots of standards for the service industry, covering education service, tourism service, psychological service, procurement service and customer contact service.

As universal standards across the world, ISO standards are applicable in all member countries; however, the specific elements and requirements of medical and health service of different countries and regions are closely related to development levels and characteristics of medical and healthcare sectors, stages of economic development, living standards, manners and local customs; as a result, ISO has given priority to product standards and technological standards in the field of medical and health service and successively issued ISO 13120-2013 Health informatics - Syntax to represent the content of healthcare classification systems - Classification Markup Language (ClaML), ISO 11135 Sterilization of health-care products series standards, ISO 11137 Sterilization of health care products -- Radiation series standards. What's more, Germany, France and Australia have developed national standards for Medical and health service- Quality Management System 
according to ISO 9001-2008 Quality Management Systems, providing technological supports for the standardized management on medical and health service in their country.

Compared with more mature service industries such as tourism service and education service, medical and health service industry is a new area for ISO; as a result, no dedicated service standard for medical and health service has been issued and implemented. It is expected that with the continuous progress of international standardization of medical and health service, a number of international standards for healthcare with global impacts will be promulgated and implemented in the near future.

\section{Japan}

As a country combining characteristics of both the developed economies of western countries and the traditional values in oriental countries of respecting and honoring the aged, Japan attaches great importance to medical and health service. On the whole, services related to the health of human body, except the medical services, are all classified as medical and health service.

In order to regulate the development of medical and health service industry and strengthen the supervision, Japan has successively issued and implemented such laws and regulations as National Health Insurance Act, School Healthcare Law, Mother and Child Healthcare Law, Health Promotion Law, Nutrition Improvement Law, Labor Safety and Health Law, The Elderly Healthcare Law, Mental Health Law, Care Service Law and Masseur, Acupuncture Doctor, and Moxibustion Doctor Law, creating complete legal framework for medical and health service industry and providing good top-level design for the standardization of medical and health service industry.

Within this framework, Japan, in the name of the Ministry of Health and Welfare and the Ministry of Education, issued dozens of medical and health service industry technical regulations, such as "Implementation Rules of 'Masseur, Acupuncture Doctor, Moxibustion Doctor Law'”(KR Heisei 2 Ministry of Health and Welfare No. 19 Decree-2004), "Confirmation Rules for Masseur, Acupuncture Doctor, and Moxibustion Doctor Training Facilities” (NKR Showa 26 Ministry of Education and Ministry of Health and Welfare No.2 Decree-2007), contributing to practical implementation of the above laws and regulations.

Similar to the situation of China, Japanese government both plays an important role in standardization work and gives full play to the roles of professional groups, ensuring the leading role of the government while embodying the principle of "Expert Drafting", to ensure that the issued standards can meet the requirements of industry development. Similar to other developed countries, at the national level, Japan also adopts nearly ten ISO standards for healthcare products and technology, including Sterilization of health-care products.

\section{Australia}

As a typical welfare state, Australia's healthcare system aims at providing the public with affordable medical and health service. Within the legal framework of National Health Law and other laws, Australia has established a universal healthcare system, the cost of which is mainly born by both the federal government and state government. Wide coverage is the biggest characteristic of the Australian universal healthcare system. Apart from Australian citizens and people granted permanent residency, New Zealand citizens and travelers from countries that have signed healthcare agreement with Australia can also enjoy the universal medical and health service.

The Australian medical and health service industry has a long history of standardized management. As early as 1974, Australian Ministry of Health established the medical and health service standards interim commission, which inspected and evaluated the process and results of medical and health service by developing a series of clinical indexes, in order to reduce potential risk; in 2000, the Healthcare Quality and Safety Commission was established to monitor and evaluate medical and health service quality; in 2004, Quality Medical and health service Commission was established, focusing on research of evidence-based theories, in order to provide technical reference for better 
medical and health service; moreover, national medical and health service accreditation system, medical and health service indexes, quality evaluation and accreditation system and crisis management guidance were successively developed, so as to regulate medical and health service providers and service delivery.

The above-mentioned explorations and practices of medical and health service quality management and standardization have achieved good results, and laid solid foundation for the study and development of relevant standards. Although traditionally Australia is not a leader in terms of service industry standardization, it is very active in medical and health service industry standardization. According to incomplete statistics, Australia has successively issued and implemented 8 national standards so far (See Table 1), which have played an important role in the sound development of Australian medical and health service industry.

Table 1. Summary of Australian National Standards for Medical and health service

\begin{tabular}{|c|c|l|}
\hline Number & \multicolumn{1}{|c|}{ No. } & \multicolumn{1}{c|}{ Title } \\
\hline 1 & AS 4846-2004 & Health care provider identification \\
\hline 2 & AS 4846-2006 & Health Care Provider Identification \\
\hline 3 & AS 5023.5-2005 & $\begin{array}{l}\text { Health supply chain messaging - Messaging rules and process } \\
\text { logic - Turnover order, turnover order status, rebate claim, rebate } \\
\text { claim response }\end{array}$ \\
\hline 4 & AS 5023.6-2005 & $\begin{array}{l}\text { Health supply chain messaging - Dataset content - Turnover } \\
\text { order status, rebate claim, rebate claim response }\end{array}$ \\
\hline 5 & HB 90.8-2006 & Medical and health services - Quality system guidelines \\
\hline 6 & HB 262-2008 & $\begin{array}{c}\text { Guidelines for pathology messaging between pathology } \\
\text { providers and health service providers }\end{array}$ \\
\hline 7 & HB 304-2007 & Guide to Australian electronic communication in health care \\
\hline 8 & HB 321-2008 & Definition of Services in Healthcare Messaging \\
\hline
\end{tabular}

\section{Acknowledgement}

This research was financially supported by China National Institute of Standardization.

\section{References}

[1] Fei HOU. Social Management and Public Service Standardization, Situation and Trend Abroad [J]. China Standardization, 2012(11).60-63+68

[2] Liang YING. Learning from Japan's Experience in Preventive Healthcare in China's Establishment of Family - based Healthcare System. [J]. Chinese Journal of Family Planning 2013 (3). 155-160 